\title{
Binder-free Two-dimensional MXene/acid activated carbon for High- performance Supercapacitors and Methylene Blue Adsorption
}

Yue Li ${ }^{\mathrm{a}}$, Canping Pan ${ }^{\mathrm{b}}$, Pascal Kamdem ${ }^{\mathrm{c}}$, Xiao-Juan Jin ${ }^{\mathrm{a}}$

${ }^{a}$ Beijing Forestry University, No.35 Tsinghua East Road, Haidian district, 100083, Beijing.

b College of Science, China Agricultural University, No.2 Yuanmingyuan west road,100193, Beijing ${ }^{c}$ School of Packaging, 130 Packaging Building East Lansing, MI 48864

\section{Materials preparation}

\section{Chemicals}

\section{Preparation of acidified activated carbon}

The waste fiberboard, which was obtained in the furniture manufacturing process containing $10 \%$ ureaformaldehyde resin adhesive of the mass, was carbonized in a high-purity $\mathrm{N}_{2}$ at the temperature increase rate of $10{ }^{\circ} \mathrm{C} / \mathrm{min}$ to the final temperature of $500^{\circ} \mathrm{C}$ and maintained for $2 \mathrm{~h}$. Then the obtained products were activated that mixed with $\mathrm{KOH}$ at the mass ratio $3: 1$ at the temperature $750{ }^{\circ} \mathrm{C}$ for $60 \mathrm{~min}$ in oven. After that, the prepared activated carbon was oxidized using the mixture of sulfuric and nitric acid as oxidization agent. Briefly, $3 \mathrm{~g}$ of activated carbon powder was mixed with $100 \mathrm{~mL}$ sulfuric and nitric acid solutions in round-bottom flask, and the solution was back flowed for $8 \mathrm{~h}$ under the temperature of $140{ }^{\circ} \mathrm{C}$ in the oil bath. After natural cooling to room temperature, the solution was centrifuged at $8000 \mathrm{rpm}$ for $30 \mathrm{~min}$ to remove large amount of agglomerate particles. During the period, the distilled water was changed for several times to neutral. 


\section{Synthesis of $\mathrm{Ti}_{3} \mathrm{C}_{2} \mathrm{~T}_{\mathrm{x}}$ nanosheets}

Typically, distilled water was added to $\mathrm{HCl}$ solution to prepare $9 \mathrm{M} \mathrm{HCl}$. Then, $2 \mathrm{~g} \mathrm{LiF}$ was added into $9 \mathrm{M} \mathrm{HCl}$ solution. After being agitated, $1 \mathrm{~g}$ of $\mathrm{Ti}_{3} \mathrm{AlC}_{2}$ powers with mesh size about $45 \mu \mathrm{m}$ was slowly added in an ice bath. Immediately followed by magnetic stirring for $24 \mathrm{~h}$ at $35^{\circ} \mathrm{C}$. The resultant was then washed and centrifuged through distilled water addition, until the supernatant reached a $\mathrm{pH}$ value of about 6 . The precipitate after centrifugation was sonicated in an Ar atmosphere. After the mixture was centrifuged for $1 \mathrm{~h}$ at $3500 \mathrm{rpm}$ to eliminate the sediment, the final collected suspension is the few layer $\mathrm{Ti}_{3} \mathrm{C}_{2} \mathrm{~T}_{\mathrm{x}}$ in the dark supernatant.

\section{Material characterization}

The TecnaiTF20 Transmission electron miscroscopy (TEM, Netherlands) was used to investigate the morphologies and microstructure. Energydispersive spectroscopy (EDS) element analysis was also performed on the same instrument in TEM mode. The morphology of the active layer was investigated by AFM. The surface areas of MXene were measured by $\mathrm{N}_{2}$ adsorption at $77 \mathrm{~K}$ using a BET surface area analyzer. Contact angle to detect hydrophilicity. X-ray diffraction (XRD) spectra were collected on $\mathrm{D} / \mathrm{max}-2550$ diffractometer with $\mathrm{Cu} \mathrm{k} \alpha$ - 1 radiation $(\lambda=0.15406 \mathrm{~nm})$. The data of X-ray photoelectron spectroscopy (XPS) were recorded on Kratos Analytical Ltd by using Al K $\alpha, \mathrm{hv}=1486.7 \mathrm{eV}$. UV-Vis spectrophotometer (Varian Cary 5000) at $664 \mathrm{~nm}$ wavelength was used to evaluate the optical 
absorbance spectra and refractive index of MXene/AAC in water for zeta potential analysis.

\section{Synthesis of MXene/AAC//AAC asymmetric capacitance.}

The asymmetric supercapacitors were assembled with the MXene/AAC hybrids as the positive electrode, acidified activated carbon as the negative electrode and polypropylene diaphragm paper as the separator. The free-standing, flexible MXene/AAC films were directly used as electrodes without any metal current collectors for supercapacitance assembly On the negative side, we used the mixture prepared by mixing the porous acidified activated carbon, acetylene black and polytetrafluoroethylene (PTFE) with ethanol in a mass ratio of 87:10:3. The mixture was treated at $105^{\circ} \mathrm{C}$ for over $4 \mathrm{~h}$ and then was pressed onto nickel foam. The electrochemical measurements of the fabricated MXene/AAC//AAC asymmetric supercapacitor were implemented in $7 \mathrm{M}$ $\mathrm{KOH}$ aqueous electrolyte in a two-electrode cell at room temperature. 

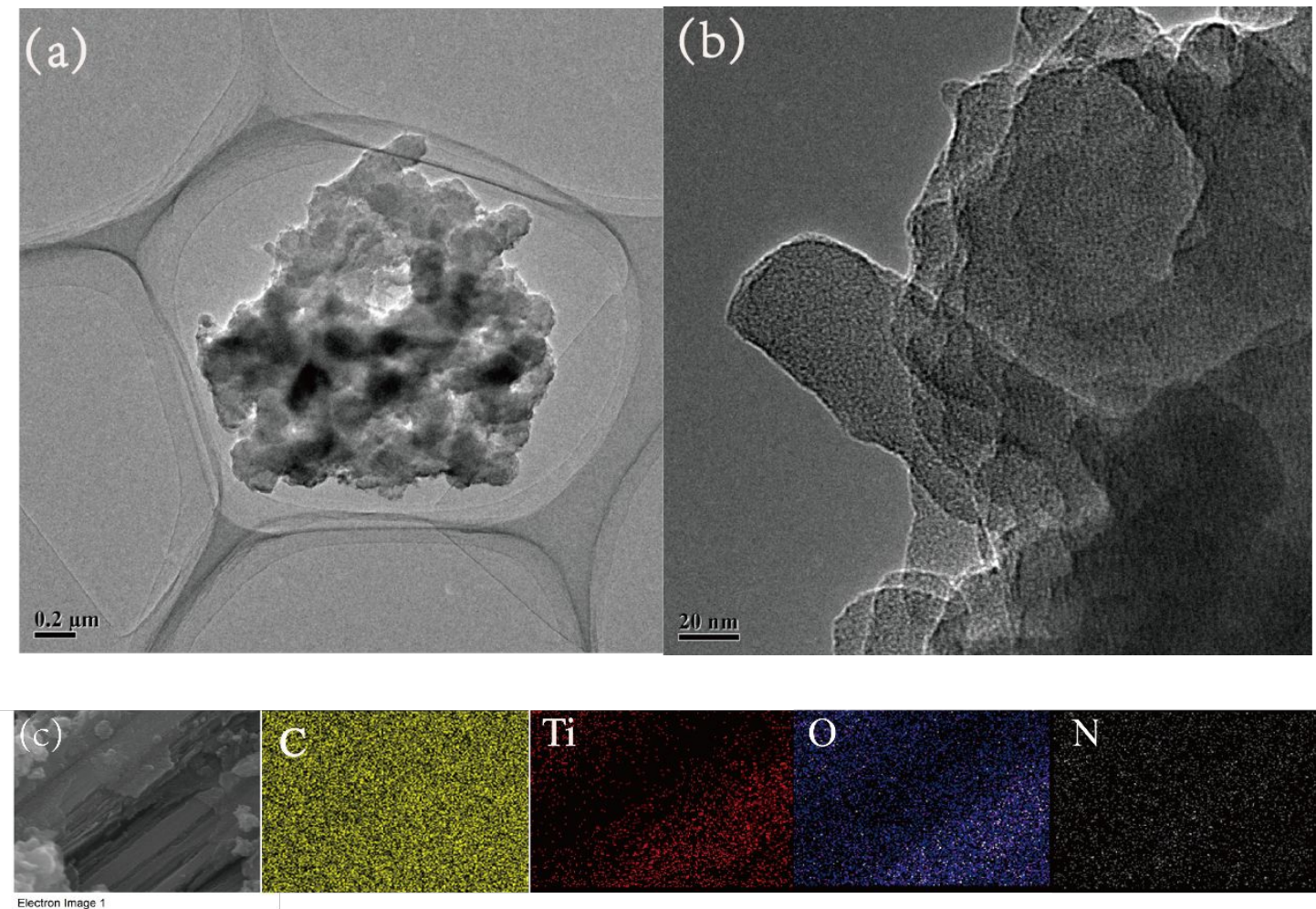

Fig.S1. (a) TEM images of MXene/AAC 2:1 (b) Magnified TEM images of MXene/AAC 2:1 (c) EDS images of MXene/AAC 2:1

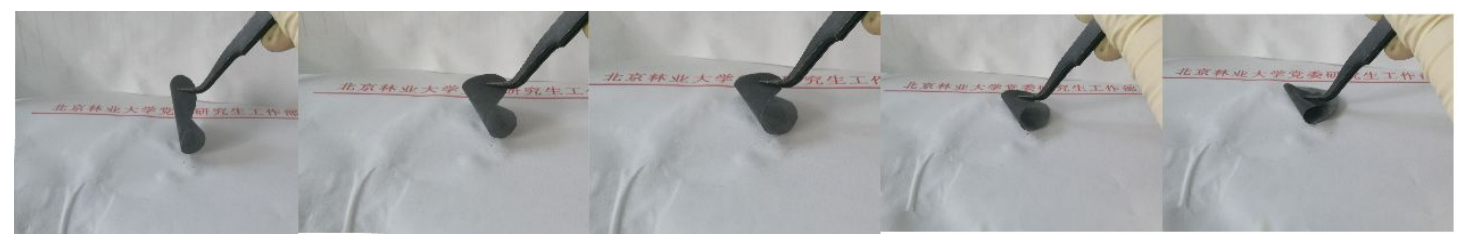

Fig.S2. Digital photos of the MXene/AAC 2:1 film
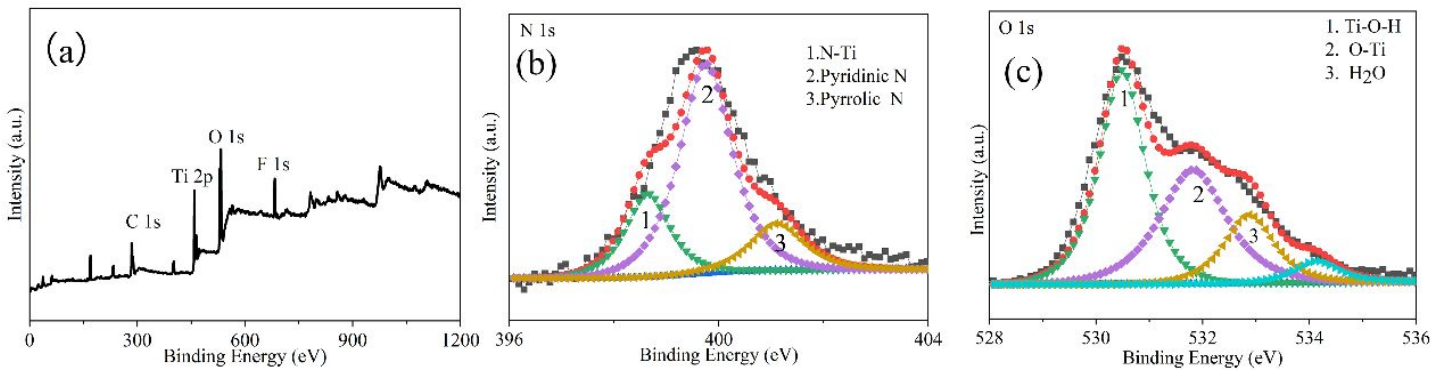

Fig.S3. (a) XPS survey (b) XPS spectra in the N1s region (c) XPS spectra in the $\mathrm{O} 1 \mathrm{~s}$ region 

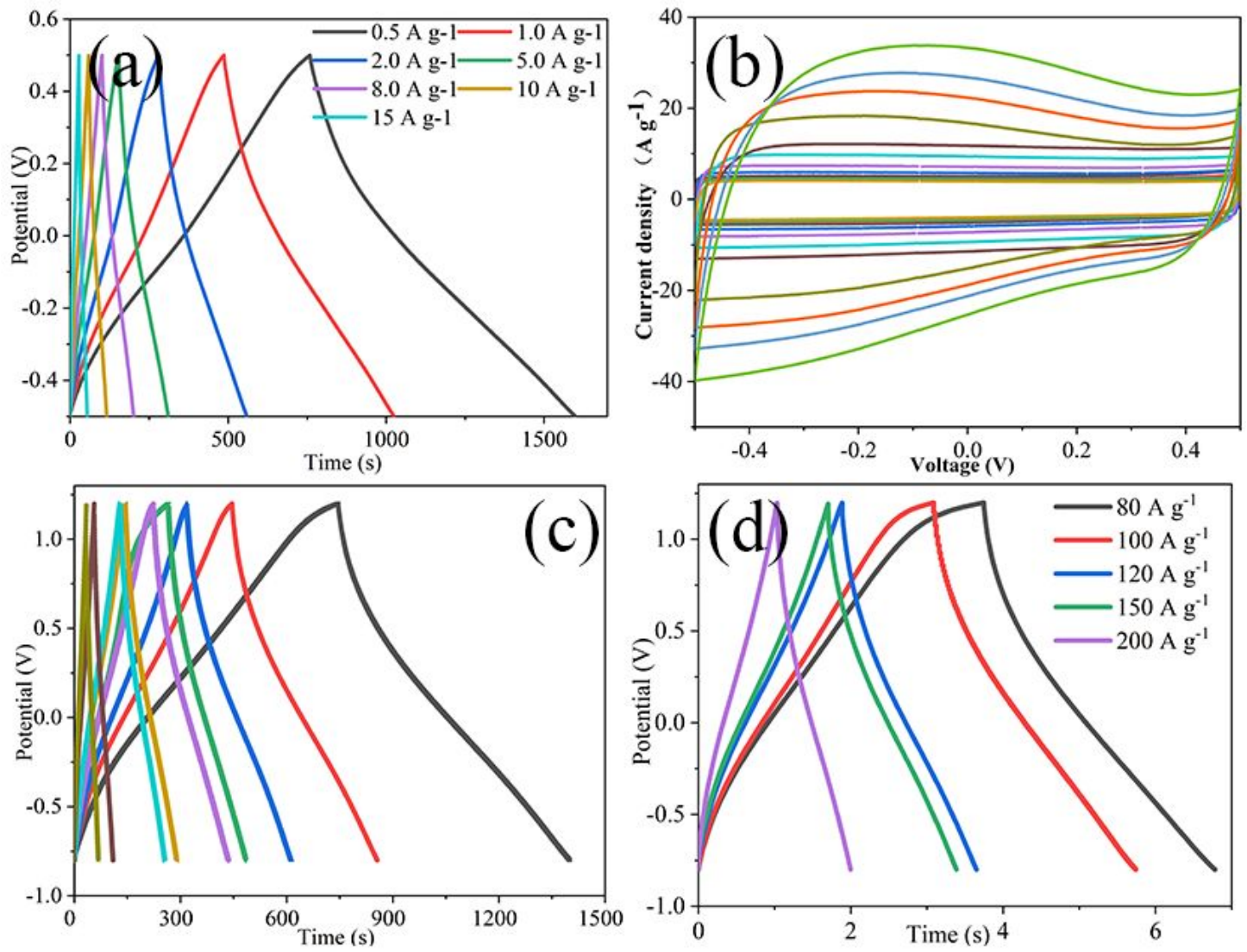

Fig.S4. (a) Electrochemical performance of MXene/AAC 2:1 (a) GCD curves of MXene/AAC 2:1 hybrid electrode collected at different current density (b) CV curves collected at different scan rates (c-d) GCD curves of MXene/AAC 2:1//AAC collected at different current density 


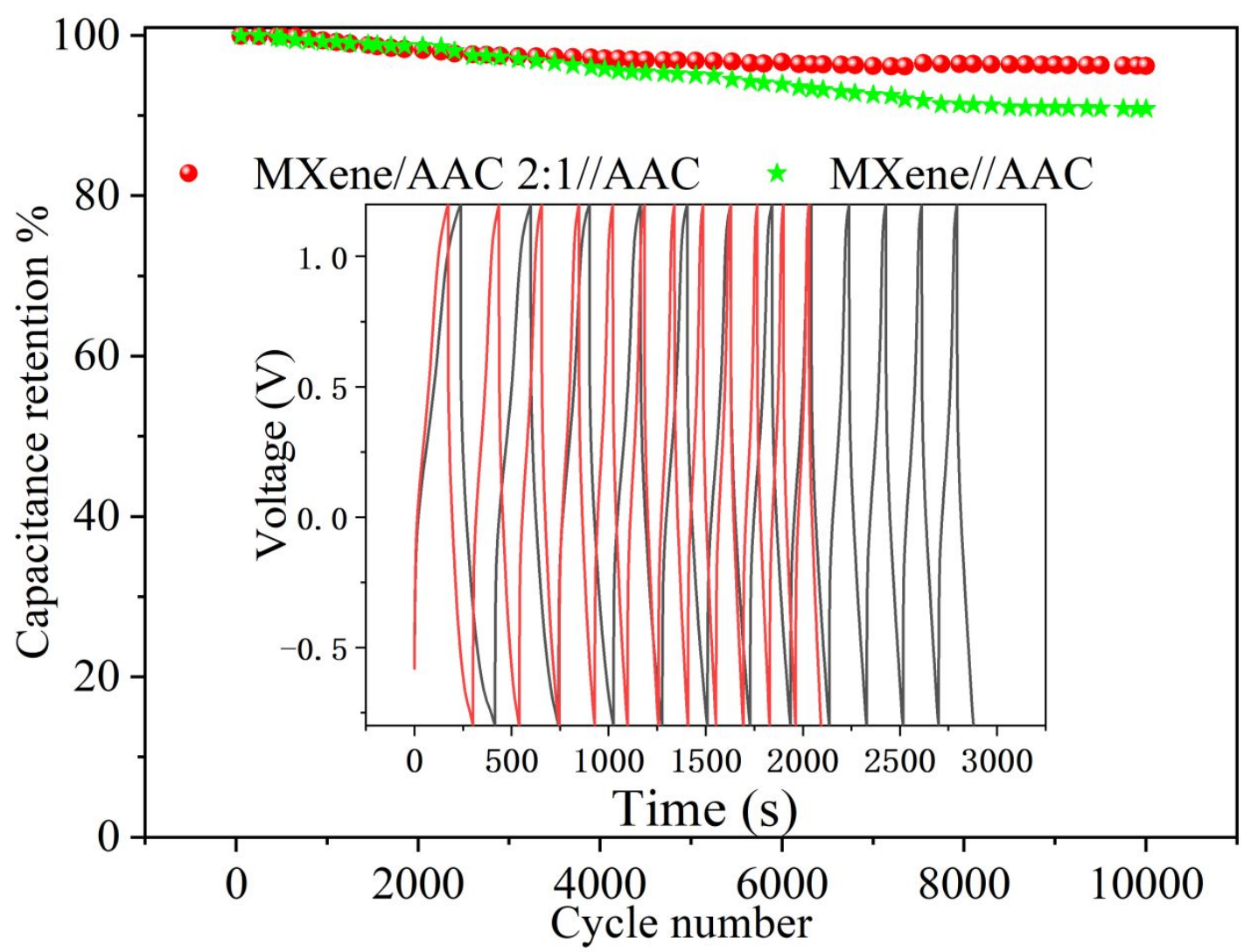

Fig.S5. cycling property of MXene/AAC//AACs and MXene/AAC 2:1//AACs at the current density of $5 \mathrm{~A} \mathrm{~g}^{-1}$. Inset: The corresponding GCD curves of $\mathrm{A}(\mathrm{B})-\mathrm{Ni}_{\mathrm{x}} \mathrm{Mo}_{\mathrm{y}}-\mathrm{MOFs} @ \mathrm{AAC} / / \mathrm{AC}$ at the last 10 cycles.

Table S1. The porosity parameters, conductivity and capacitance of AAC, pure MXene and MXene/AAC hyrids

\begin{tabular}{llllll}
\hline Sample & $\begin{array}{c}\text { Conducti } \\
\text { vity } \\
(\mathrm{S} \mathrm{cm}-1)\end{array}$ & $\begin{array}{c}\text { Density } \\
\left(\mathrm{g} \mathrm{cm}^{-3}\right)\end{array}$ & $\begin{array}{c}\mathrm{S}_{\mathrm{BET}} \\
\left(\mathrm{m}^{2} \mathrm{~g}^{-1}\right)\end{array}$ & $\begin{array}{c}\mathrm{V}_{\text {tot }} \\
\left(\mathrm{cm}^{3} \mathrm{~g}^{-1}\right)\end{array}$ & $\begin{array}{c}\text { Capacitance } \\
\mathrm{C}_{\mathrm{m}}\left(\mathrm{F} \mathrm{g}^{-1}\right)\end{array}$ \\
\hline AAC & 17 & 0.211 & 2089 & 1.42 & 264 \\
MXene/AAC 1:1 & 88 & 0.216 & 1822 & 1.16 & 357 \\
MXene/AAC 2:1 & 191 & 0.309 & 1651 & 1.07 & 378 \\
MXene/AAC 3:1 & 262 & 0.336 & 1256 & 0.98 & 369 \\
MXene/AAC 5:1 & 357 & 0.406 & 693 & 0.69 & 363 \\
\hline
\end{tabular}




\begin{tabular}{llllll}
\hline MXene & 3206 & 2.01 & 18.92 & 0.008 & 314 \\
\hline
\end{tabular}

Table S2. Kinetic parameters and correlation coefficients for BA adsorption

\begin{tabular}{lccc|ccc}
\hline \multirow{2}{*}{ Material } & \multicolumn{3}{c|}{$\begin{array}{c}\text { Pseudo-first-order } \\
\text { kinetic model }\end{array}$} & \multicolumn{3}{c}{ Pseudo-second-order } \\
& $\mathbf{q}_{\mathbf{e}}$ & $\boldsymbol{k}_{\boldsymbol{I}}\left(\mathbf{h}^{-1}\right)$ & $\mathbf{R}^{\mathbf{2}}$ & $\mathbf{q}_{\mathbf{e}}$ & $\boldsymbol{k}_{\boldsymbol{I}}\left(\mathbf{h}^{-1}\right)$ & $\mathbf{R}^{\mathbf{2}}$ \\
& $\mathbf{m g / g})$ & & & $\mathbf{( m g / g )}$ & & \\
\hline MXene & 29.8 & 0.025 & 0.526 & 113.5 & 0.062 & 0.997 \\
MXene/AAC1:1 & 38.3 & 0.028 & 0.569 & 108.1 & 0.055 & 0.997 \\
MXene/AAC2:1 & 59.6 & 0.020 & 0.831 & 132.6 & 0.035 & 1.00 \\
MXene/AAC3:1 & 58.3 & 0.031 & 0.756 & 119.5 & 0.060 & 0.998 \\
MXene/AAC5:1 & 66.2 & 0.032 & 0.712 & 123.4 & 0.071 & 0.999 \\
\hline
\end{tabular}

Table S3 XPS peak fitting results for C 1s and O 1s region of MXene power and MXene/AAC with different MXene proportion

\begin{tabular}{ccccccc|cccc}
\hline Materials & \multicolumn{9}{c}{ C 1s (at. \%) } & \multicolumn{3}{c}{ O 1s (at. \%) } \\
\cline { 2 - 10 } & C-Ti & $\begin{array}{c}\text { C- } \\
\text { Ti-O }\end{array}$ & C-C & $\begin{array}{c}\text { C- } \\
\text { N }\end{array}$ & C-O & $\begin{array}{c}\text { O= } \\
\text { C-O }\end{array}$ & $\begin{array}{c}\text { Ti- } \\
\text { O-H }\end{array}$ & $\begin{array}{c}\text { O- } \\
\text { Ti }\end{array}$ & $\mathbf{H}_{2} \mathbf{O}$ \\
\hline \multicolumn{1}{c}{ MXene } & 19.2 & 9.1 & 57.8 & 0.3 & 9.6 & 4.0 & 28.6 & 41.9 & 29.5 \\
MXene/AAC1:1 & 1.5 & 3.8 & 66.8 & 1.9 & 22.6 & 3.4 & 43.7 & 50.5 & 5.8 \\
MXene/AAC2:1 & 2.5 & 5.0 & 63.6 & 1.5 & 21.2 & 3.2 & 43.8 & 48.9 & 7.3 \\
MXene/AAC3:1 & 5.8 & 6.1 & 62.7 & 2.0 & 19.6 & 3.8 & 40.6 & 48.2 & 11.2 \\
MXene/AAC5:1 & 7.3 & 7.4 & 62.8 & 1.8 & 16.5 & 4.2 & 32.8 & 49.3 & 17.9 \\
\hline
\end{tabular}




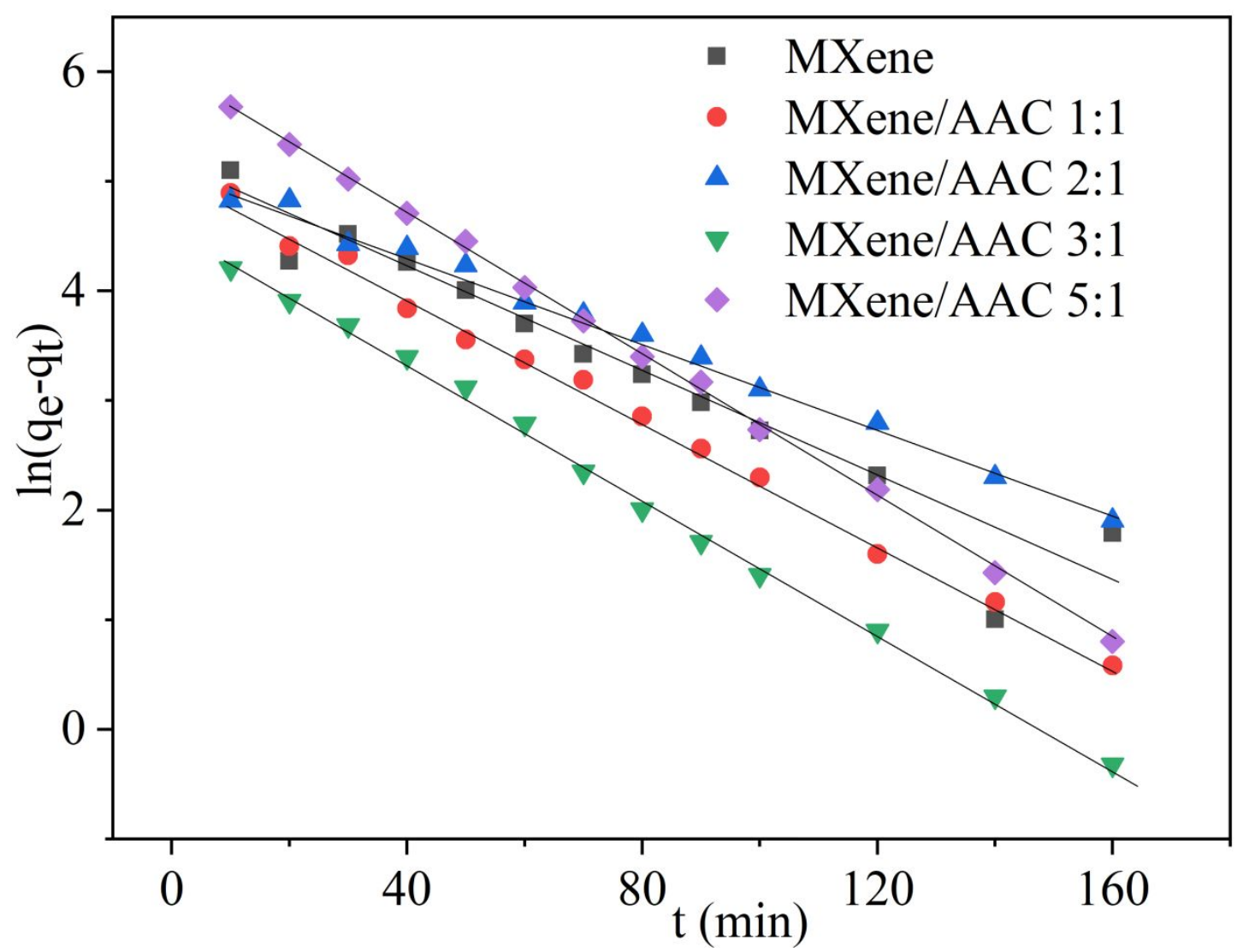

Fig.S6. (a) Linearized form of pseudo-first-order (b) Linearized form of pseudosecondorder

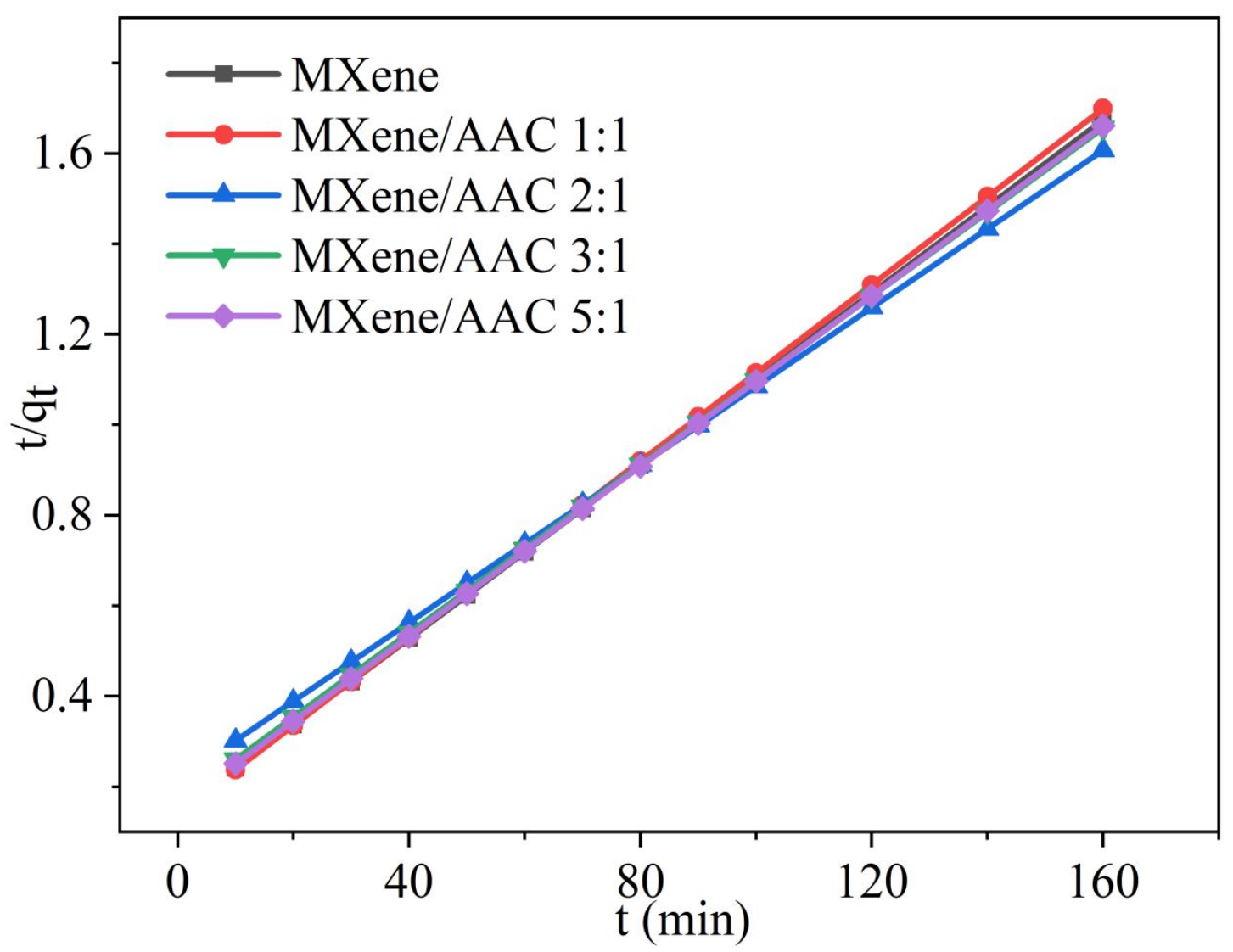


Fig.S7. (a) Linearized form of pseudo-secondorder 